\title{
Injection Gate Definition for Improving the Accuracy of Liquid Composite Molding Process Simulation
}

\author{
Chensong Dong \\ Rakon Limited, Private Bag 99943, Newmarket, Auckland 1149, New Zealand \\ chensongdong@yahoo.com
}

\begin{abstract}
Computer simulation has become an efficient and cost-effective tool for the Liquid Composite Molding (LCM) processes, including the RTM, VARTM, and resin infusion, compared to trial-and-error. The purpose of simulation is to accurately reflect the real situation. Since the simulation is predominantly based on the Control Volume Finite Element Method (CVFEM), the boundary conditions such as gate and vent definition need to be properly defined. In this paper, the errors of the CVFEM based mold filling simulation were analyzed. The error sources were identified as the mesh near gates and vents, and gate definition. By conducting 3-D and 2-D simulation case studies, the influence of the gate definition on the simulation result was studied. Because many composite parts are shells and can be regarded as surfaces, 2-D simulation is favorable because of the better efficiency and simpler pre-processing. For this purpose, a method for mold filling simulation incorporating the gate size effect — the Effective Gate Method (EGM) was developed. This method was validated through case studies. It shows that the EGM provides an effective and efficient approach to the CVFEM mold filling simulation incorporating the effect of injection gate size.
\end{abstract}


Keywords: Liquid Composite Molding (LCM), mold filling, simulation, Control Volume Finite Element Method (CVFEM), gate definition

\section{Introduction}

Composite components are gaining more and more applications because of their superior properties. Among the processing techniques, because of the advantages of relatively low equipment and tooling costs, short cycle times and excellent design flexibility, liquid composite molding (LCM) processes have attracted considerable attention and gained the status as a preferred method for manufacturing structural composite components.

Two common LCM processes are resin transfer molding (RTM) and vacuum assisted resin transfer molding (VARTM). The RTM process can be generally divided into four steps as shown in Figure 1 [1]. In the first step, dry reinforcements are cut and/or shaped into preformed pieces and then placed in a prepared mold cavity. This is usually called preform loading. After the mold is closed and clamped tightly, resin is injected into the mold cavity, where it flows through the reinforcement preform, expels the air in the cavity, and "wets out" or impregnates the reinforcement. This step, which is considered the most critical in the RTM process, is called mold filling. When excessive resin begins to flow out of the vent area of the mold, resin injection is stopped and the curing step begins. Curing can take from several minutes to several hours. When curing is complete, the component is removed from the mold. This final step is called demolding. 
In the VARTM process, as shown in Figure 2, only one rigid mold piece is used and the other mold piece is a vacuum bag. A highly permeable distribution medium is incorporated into preform as a surface layer. During infusion, the resin flows preferentially across the surface and simultaneously through the perform thickness enabling large parts to be fabricated.

Complete filling of the mold with adequate wetting of the fibrous preform is critical in the LCM. Incomplete impregnation in the mold leads to defective parts containing dry spots. In order to achieve good quality, processing parameters such as the locations and numbers of gates and vents need to be carefully selected.

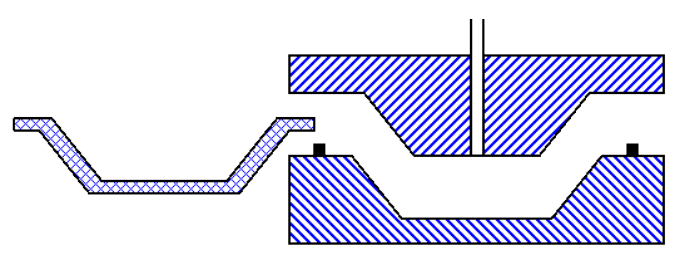

Step 1: Load preform

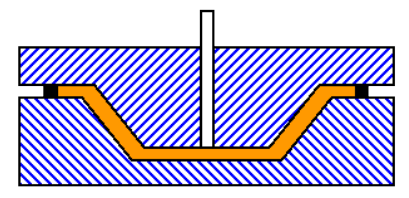

Step 3: Cure

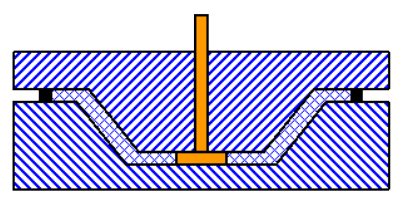

Step 2: Inject resin

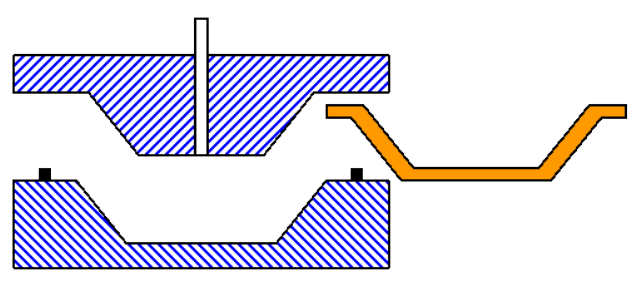

Step 4: Demold

Figure 1: Resin transfer molding process 


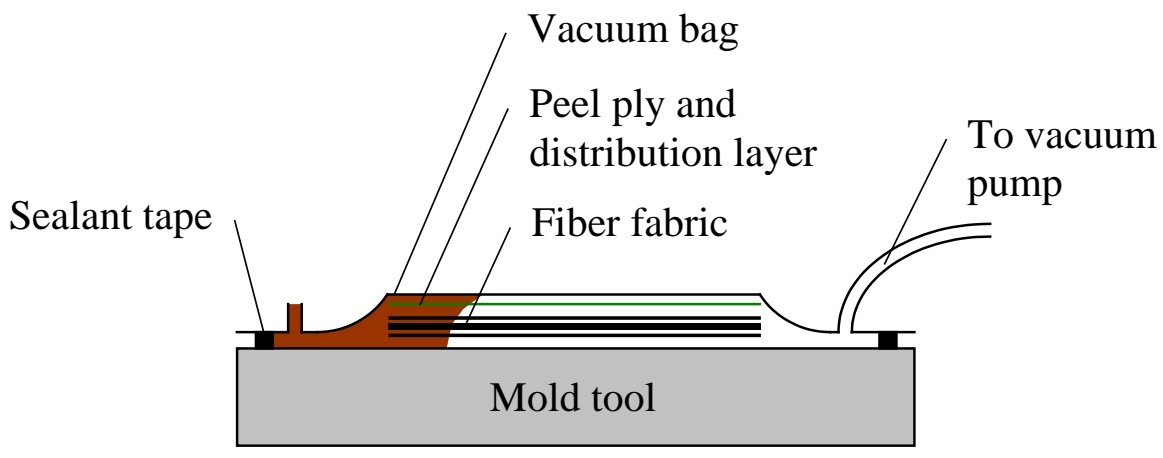

Figure 2: Vacuum assisted resin transfer molding process

Traditionally, trial-and-error techniques are widely applied in the composite industry, which mainly depend on the experience and skills of operators. It is very costly and time-consuming. With the development of computing technology, simulation has become a powerful tool for the process design and optimization. The mathematical models for the LCM mold filling are solving for a set of partial differential equations. For this purpose, several methods including finite difference method (FDM), finite element method (FEM) and boundary element method (BEM) were employed by various researchers. FDM was the first attempt used to simulate a two-dimensional RTM process [2]. By comparing with experimental results, it was proven that due to edge effects, the computing errors were over a reasonable range, which limited further application. Um et al. [3] studied two-dimensional flat molds where the permeability and the resin viscosity were constant applying the BEM and concluded that it took less time to generate mesh at each time step than required by FDM or FEM. Yoo et al. [4] and Osswald et al. [5] determined that under the limitations of simple geometry parts and isothermal Newtonian problems, the BEM method gave very accurate simulation results.

When FEM is used, mold filling simulation is based on a time dependent solution of an unsteady boundary value problem. Because of the evolving boundary it is difficult to generate a 
fixed mesh suitable for all the successive calculation steps of a filling simulation. Re-meshing algorithms have been studied [6-7]. Alternatively, the Control Volume Finite Element Method (CVFEM) has been the predominant method for process simulation [8-15]. It forms and solves a set of equations for nodal control volumes as if they were finite elements. Mesh regeneration is not required, which makes the computation more efficient. Three major steps are needed in the CVFEM flow simulation: (1) use the FE solution to obtain the pressure distribution in the resinfilled region; (2) calculate the resin flow rates; and (3) trace the resin flow front [16].

Traditionally, the injection gate was modeled by a single node in the CVFEM based mold filling simulation. This yields large error in some situations and causes singularity problems. Modi et al. [17] developed an analytical solution relating the fill time to the injection gate radius for a constant pressure injection from a spherical injection gate into an isotropic media. Simacek et al. [18] used special gate elements embedded in the mesh around the injection locations. Instead of adjusting the geometrical modeling of the injection location, the adjacent elements use modified shape functions to accurately model pressure field in the neighborhood of small radial inlet. Until now, the gate definition in CVFEM based mold filling simulation is still lack of a thorough study. In this paper, the gate defining methods for 3-D and 2-D simulation were studied respectively. Because many composite parts are shells and can be regarded as surfaces, 2-D simulation is favorable because of the better efficiency and simpler pre-processing. For this purpose, a method for mold filling simulation incorporating the gate size effect — the Effective Gate Method (EGM) was developed. 


\section{Control Volume Finite Element Method (CVFEM)}

The flow of a viscous fluid through an anisotropic, homogenous, porous medium is represented by Darcy’s law [19]:

$$
\mathbf{v}=-(1 / \phi \mu) \mathbf{K} \cdot \nabla p
$$

For an incompressible fluid, the mass conservation equation can be reduced to the form:

$$
\nabla \cdot \mathbf{v}=0
$$

Equation 2 can be integrated over a control volume and leads to:

$$
\iiint_{V} \nabla \cdot \mathbf{v} d V=0
$$

Using the Divergence theorem (Gauss’s theorem), the control volume integral can be transformed into a control surface integral. Thus, Equation 3 can be written as:

$$
\iint_{S} \mathbf{n} \cdot \mathbf{v} d S=0
$$

Substituting Equation 1 into Equation 4 yields:

$$
\iint_{S}(1 / \phi \mu) \mathbf{n} \cdot \mathbf{K} \cdot \nabla p d S=0
$$

Equation 5 is the working equation for solving the problems of flow through anisotropic porous media and is a combination of the mass and momentum equations, while the momentum equation is represented by using the Darcy’s law.

In order to solve such moving boundary problems as the resin flow front advances using the traditional finite element method, it requires the computation domain redefinition and mesh regeneration. Mesh regeneration needs a large amount of computation time as the domain 
becomes complicated. Alternatively, the control volume finite element method is used. The control volume formation is illustrated using the element configuration. As shown in Figure 3, each four-node quadrilateral element is divided into four sub-areas by connecting the centroid to the midpoints of all four sides. A control volume is composed of four sub-areas (A), two subareas (B) or one sub-area (C), which have a common node at the center of the control volume. The CVFEM forms and solves a set of equations for nodal control volumes as if they were finite elements, does not require mesh regeneration. Thus, the computation is more efficient.

The boundary conditions for mold filling simulation are as follows:

At the flow front:

$$
p=0 \text {. }
$$

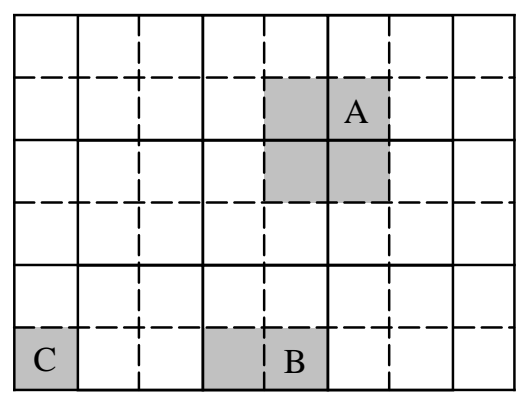

Figure 3: Construction of control volumes

At the inlet gates:

For constant pressure: $p=p_{0}$;

For the constant flow rate: $\mathbf{v}=\mathbf{v}_{0}$.

At the mold boundaries: 


$$
\partial p / \partial \mathbf{n}=0
$$

It is assumed that at the beginning of mold filling, the control volumes enclosing the inlet nodes are filled with resin. At the flow front, a parameter $f$ is used to represent the status of each control volume in the flow domain. If the control volume has not been occupied by the fluid, $f$ is equal to zero. If the control volume is partially filled, $f$ is equal to the volume fraction of the fluid occupying the control volume. $f$ factor is set to 1 if the volume is completely filled by advancing fluid. The control volumes with $f$ values varying between 0 and 1 are considered flow front elements. The pressure in these partially filled flow front control volumes is set to the ambient pressure. With the aforementioned boundary conditions, the set of linear algebraic equations can be solved to determine the pressure field at each time step during mold filling. Based on the calculated pressure field, the velocity field can then be computed using Darcy's law.

The time increment is selected in such a way that a control volume will be fill at each time step. Sometimes, several control volumes can be filled simultaneously. After $f$ values are updated, another pressure computation is performed for all the fully filled control volumes. The process is repeated until the whole mold is filled [9].

\section{Errors of CVFEM Based Mold Filling Simulation}

\subsection{Basic Assumptions}

Several assumptions are made for the CVFEM based mold filling simulation used in this study. 
1. Despite the fact that resin is usually non-Newtonian fluid, a constant viscosity value is used in simulation. This assumption can be made because of the low Reynolds number.

2. A uniform permeability and porosity is assumed.

3. For simplicity, the race tracking phenomenon is considered as a noise factor. Thus, no race tracking is assumed.

\subsection{Effect of Mesh}

It is well agreed that the simulation accuracy will improve when a finer mesh is used. For understanding the influence of mesh on simulation, a $100 \mathrm{~mm} \times 100 \mathrm{~mm}$ flat panel as shown in Figure 4 was simulated using two different mesh densities. Due to symmetry, half of the panel was meshed, as shown in Figure 5. The two different meshes consist of 66 nodes, 50 elements and 861 nodes, 800 elements respectively. The resin was injected through a single port. $p_{0}=0.1 \mathrm{MPa} ; \eta=200 \mathrm{cP} ; K_{11}=K_{22}=100$ Darcy; $\phi=0.5$. The mold filling process simulated using these two different meshes is shown in Figure 6. When the coarser mesh is used, the computation time is $1 \mathrm{~s}$ and the mold filling time is $125 \mathrm{~s}$. When the finer mesh is used, the computation time is $126 \mathrm{~s}$ and the mold filling time is $171 \mathrm{~s}$. The mold filling time simulated using the coarser uniform mesh is $26.9 \%$ less than that using the finer uniform mesh. 


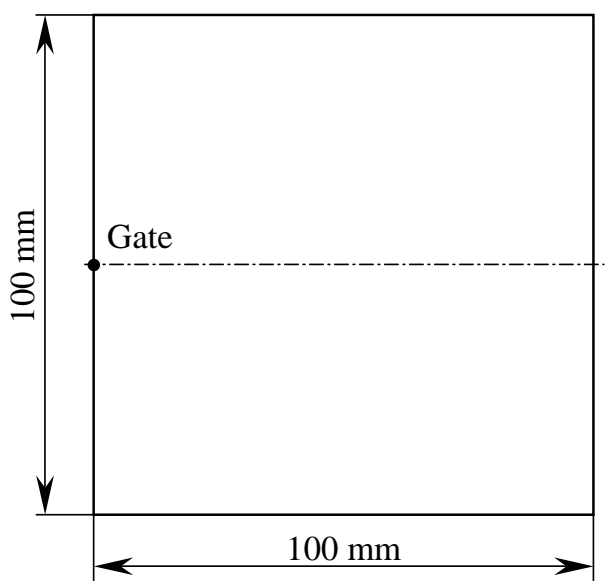

Figure 4: Single port injected $100 \mathrm{~mm} \times 100 \mathrm{~mm}$ flat panel
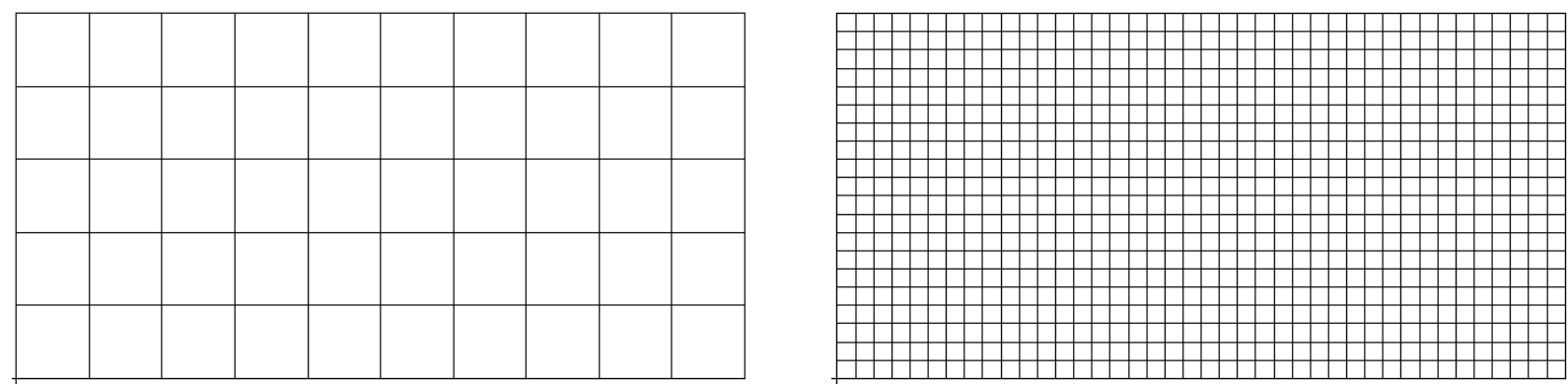

Figure 5: Meshes of two densities

Left: 66 nodes and 50 elements Right: 861 nodes and 800 elements
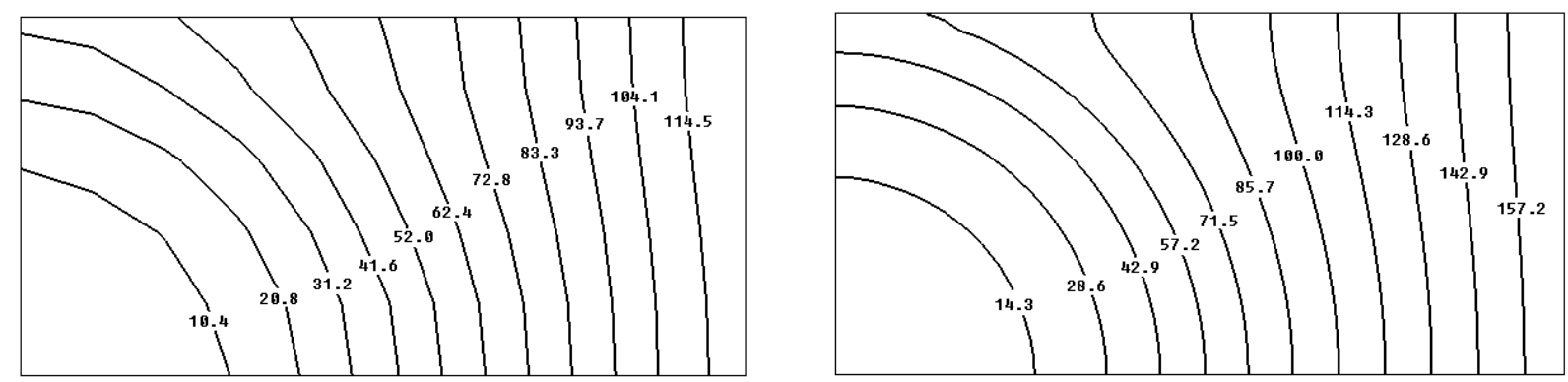

Figure 6: Mold filling process of two densities (unit: s)

Left: 66 nodes and 50 elements Right: 861 nodes and 800 elements 
Since the pressure field is computed by FEA, it is significantly affected by mesh density. The pressure distribution simulated using these two different meshes is shown in Figure 7. It shows that pressure distribution is extremely sensitive to the mesh density near the gate and vent. The difference in the mold filling time is caused by the difference in pressure distribution.
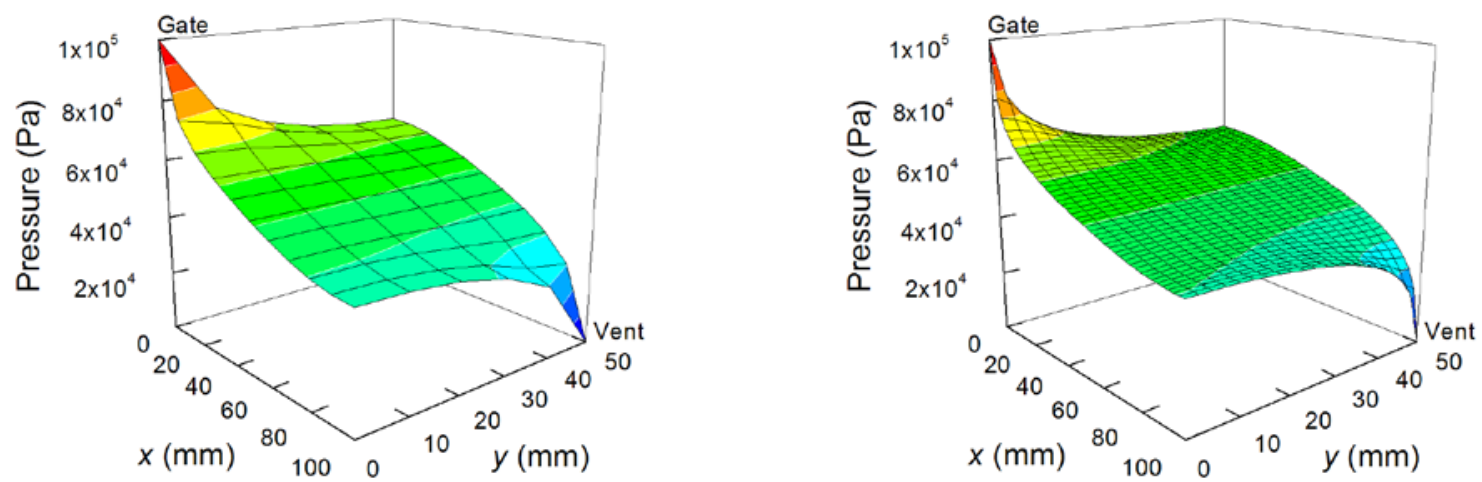

Figure 7: Pressure distribution of two densities (unit: Pa)

Left: 66 nodes and 50 elements Right: 861 nodes and 800 elements

The simulated mold filling time and computation time are plotted against the mesh density in Figure 8. It shows that when the mesh refines, the simulation approaches to the exact solution, which is the grid convergence. However, as the mesh density increases, the computation time increases tremendously. When the mesh density changes from 10 to 100, the computation time increases over three orders of magnitudes and the simulation becomes less efficient. To achieve acceptable accuracy while maintaining the simulation efficiency, the mesh density should be typically chosen to be 40 . In the further analysis, the same mesh density is used to eliminate the effect of grid convergence. 


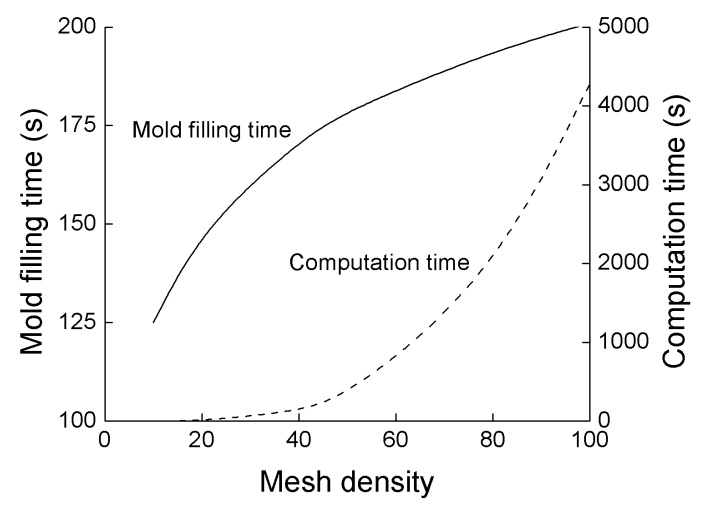

Figure 8: Influence of mesh density on simulation

\subsection{Effect of Gate Definition}

Besides mesh density, the gate definition also has a significant effect on mold filling simulation. Traditionally, the injection gate is defined by a single node. However, this will cause significant difference from the actual mold filling process when the gate is large with regard to the molding thickness. In addition, the single node gate definition causes singularity problems.

With the same flat panel as an example, the gates defined by one node, two nodes and three nodes respectively are shown in Figure 9. The corresponding mold filling processes are shown in Figure 10. It shows that the more nodes used as the gate, the larger the gate size and thus the shorter the mold filling time. 

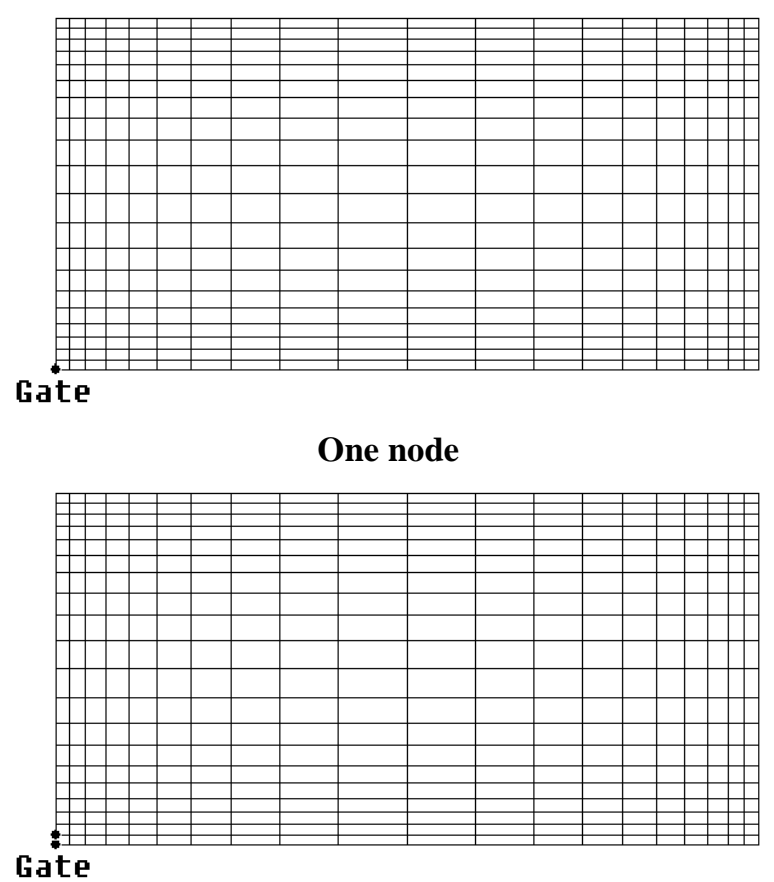

Two nodes

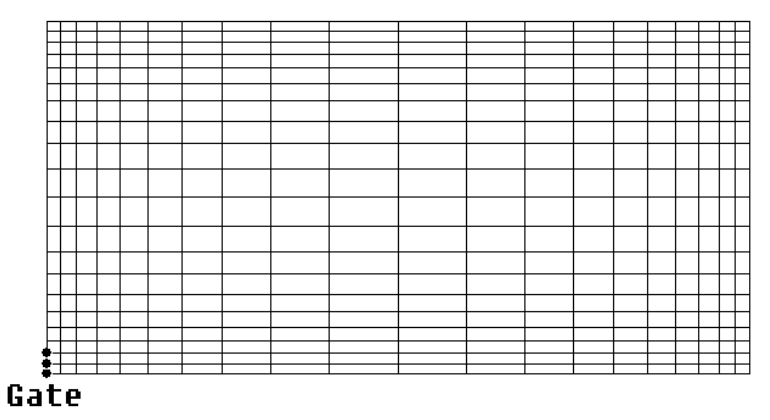

Three nodes

Figure 9: Gate definition by different numbers of nodes 

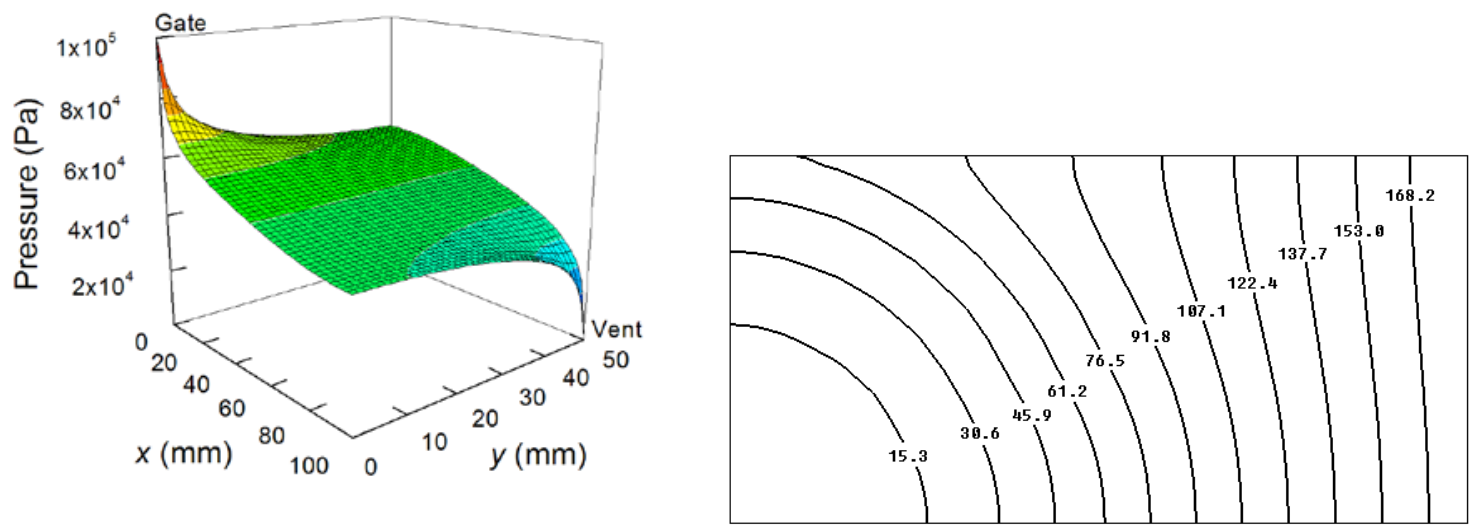

\section{One node}
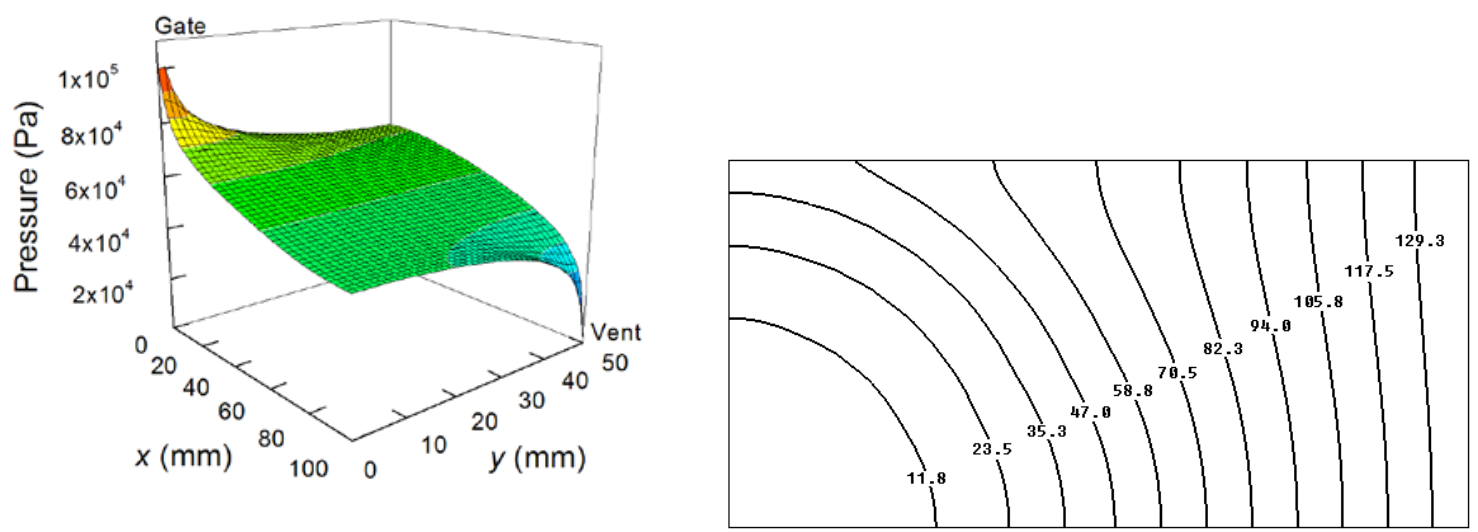

Two nodes
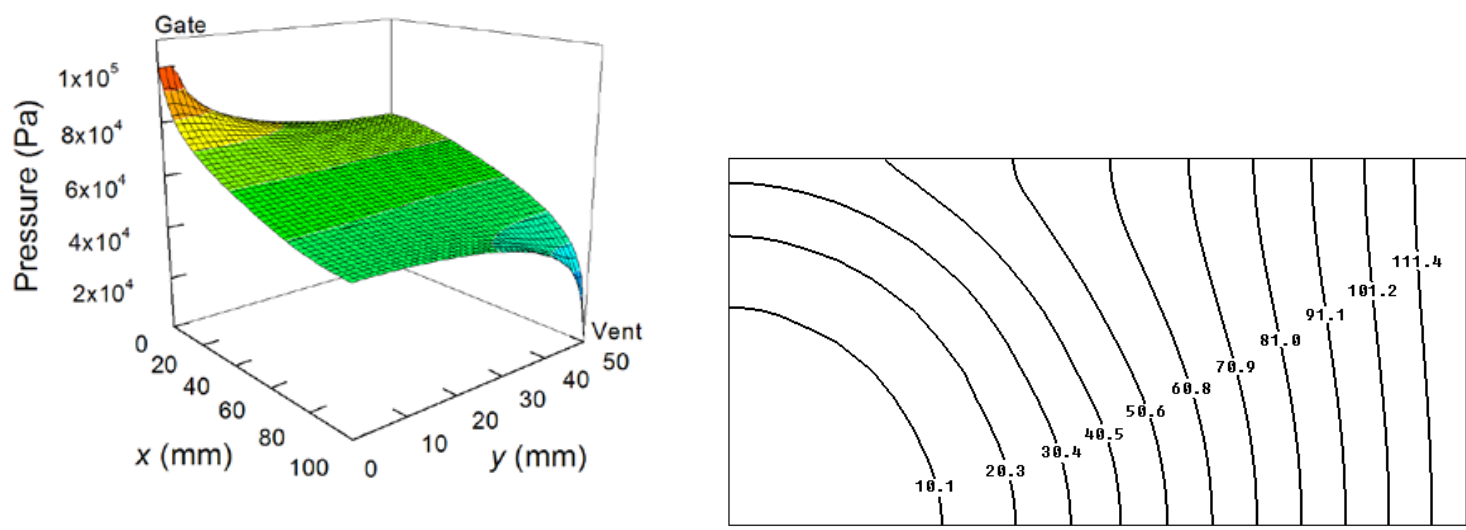

Three nodes

Figure 10: Effects of gate definition on pressure distribution and mold filling process 


\subsection{Summary of Error Sources}

From the preliminary studies, the main error sources of the CVFEM based mold filling simulation can be summarized as

1. The mesh density near gates and vents: The pressure distribution is extremely sensitive to the mesh density near the gates and vents. The finer the mesh near the gates and vents, the more accurate the simulation. The mesh density near gates also determines the size of the control volumes that enclose the gates. The control volumes enclosing the gates are assumed filled at the beginning of mold filling, which is not the real. Thus, the larger these control volumes, the less accurate the simulation.

2. The gate definition: The gate definition affects the simulation result significantly. The traditional single node definition neglects the effect of injection gate size. In addition, the single node definition causes singularity problems.

In order to improve the simulation accuracy, a finer mesh is needed for the areas near the gates and vents. The injection gates should be defined properly to incorporate the size effect.

\section{Injection Gate Definition}

\subsection{3-D Gate Definition}

In the LCM, the injection gate is usually a circular cross-section channel. The actual resin flow through a circular cross-section channel and the flow front development are shown in Figure 11. At the boundary of tube, the flow velocity is 0 . Thus, average velocity is given by 


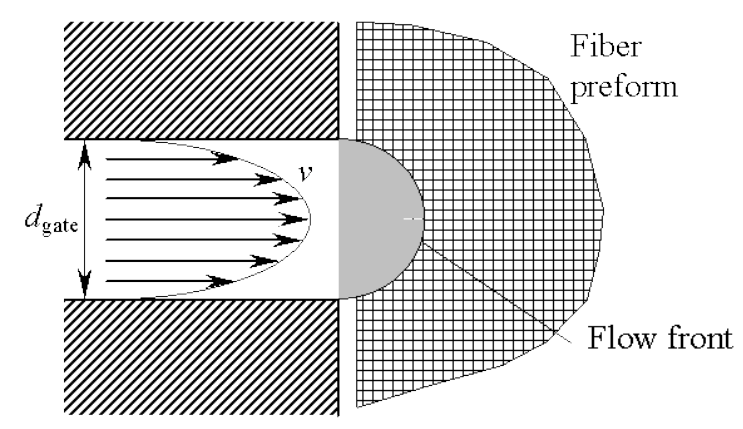

Figure 11: Actual velocity profile of resin flow

$$
v=v_{m} / 2
$$

where $v_{m}$ is given by [20]

$$
v_{m}=(\Delta p / \Delta x) d_{\text {gate }}^{2} /(16 \eta)
$$

The volumetric flow rate is given by

$$
Q=\pi\left(v_{m} / 2\right)\left(d_{\text {gate }} / 2\right)^{2}
$$

In the case of constant pressure injection mold filling simulation, since the boundaries are not considered, it is assumed that the velocity profile is constant along the cross section and the flow front develops as shown in Figure 12. The average velocity is $v_{m}$. Since the volumetric flow rate should be the same as the actual flow rate, thus,

$$
Q=\pi v_{m}\left(\hat{d}_{\text {gate }} / 2\right)^{2}
$$

The gate diameter in simulation is given by

$$
\hat{d}_{\text {gate }}=d_{\text {gate }} / \sqrt{2}
$$




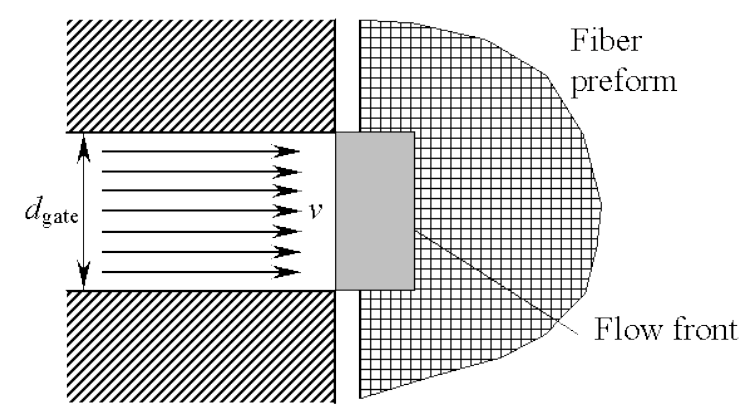

Figure 12: Velocity profile of resin flow in simulation

For the purpose of illustrating this approach, the $100 \mathrm{~mm} \times 100 \mathrm{~mm}$ flat panel shown in Figure 4 was simulated by 3-D CVFEM. The molding thickness chosen is $3.175 \mathrm{~mm}, 6.35 \mathrm{~mm}$, and $9.525 \mathrm{~mm}$, respectively, and the actual gate diameter and diameter used in simulation are shown in Table 1 . The processing conditions are $p_{0}=0.1 \mathrm{MPa} ; \eta=200 \mathrm{cP} ; K_{11}=K_{22}=$ 100 Darcy; $K_{33}=20$ Darcy; $\phi=0.5$. Half of the molding was modeled due to symmetry.

Table 1: Actual gate diameter and gate diameter used in simulation

\begin{tabular}{l|l|l}
\hline$h(\mathrm{~mm})$ & $d_{\text {gate }}(\mathrm{mm})$ & $\hat{d}_{\text {gate }}(\mathrm{mm})$ \\
\hline \multirow{4}{*}{3.175} & 1.588 & 1.123 \\
\cline { 2 - 3 } & 2.381 & 1.684 \\
\cline { 2 - 3 } & 3.175 & 2.245 \\
\hline \multirow{5}{*}{6.350} & 1.588 & 1.123 \\
\cline { 2 - 3 } & 2.381 & 1.684 \\
\cline { 2 - 3 } & 3.175 & 2.245 \\
\cline { 2 - 3 } & 4.763 & 3.368 \\
\cline { 2 - 3 } & 6.350 & 4.490 \\
\hline \multirow{5}{*}{9.525} & 1.588 & 1.123 \\
\cline { 2 - 3 } & 2.381 & 1.684 \\
\cline { 2 - 3 } & 3.175 & 2.245 \\
\cline { 2 - 3 } & 4.763 & 3.368 \\
\cline { 2 - 3 } & 6.350 & 4.490 \\
\cline { 2 - 3 } & 9.525 & 6.735 \\
\hline
\end{tabular}

The mesh at the gate is generated in such a way that the diameter of the control volume filling at the beginning of injection is the gate diameter used in simulation. For example, when 
the molding thickness is $3.175 \mathrm{~mm}$ and the gate diameter is $2.381 \mathrm{~mm}$, the mesh for the gate is shown in Figure 13. Eight nodes are used as gate nodes so that the diameter of the control volume filled at the beginning of injection is $1.684 \mathrm{~mm}$, as represented by the shaded area. The mesh consisting of 1554 nodes and 1720 elements and the corresponding mold filling process are shown in Figure 14. The computation time and mold filling time are $17 \mathrm{~m}$ and 173s, respectively.

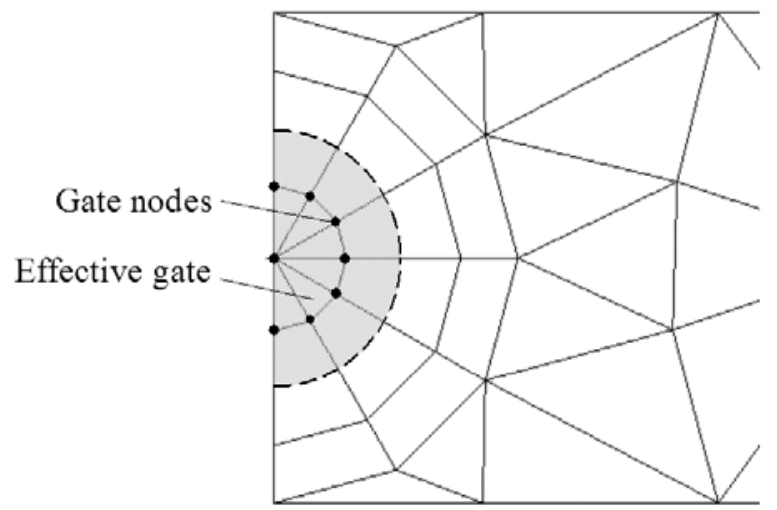

Figure 13: 3-D mesh at the gate when $h=3.175 \mathrm{~mm}$ and $d_{\text {gate }}=2.318 \mathrm{~mm}$
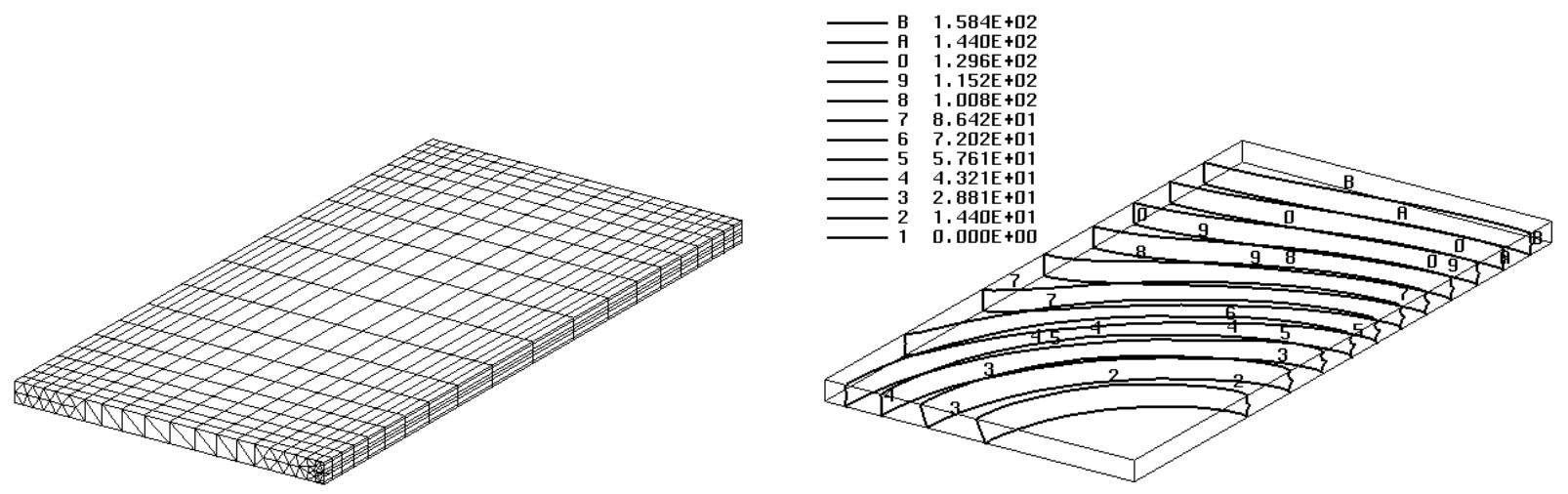

Figure 14: 3-D mesh and mold filling process when $h=3.175 \mathrm{~mm}$ and $d_{\text {gate }}=2.318 \mathrm{~mm}$ 
For comparison, the 3-D simulation was repeated with the single node gate definition.

The mold filling time is 298s, which is $67.4 \%$ longer. Thus, the single node gate in the 3-D mold filling simulation yields an erroneous result.

The complete 3-D simulation result using the 3-D gate defining method is shown in Table 2.

Table 2: 3-D CVFEM simulation using the 3-D gate defining method

\begin{tabular}{c|c|c|c|c|c}
\hline$h(\mathrm{~mm})$ & $d_{\text {gate }}(\mathrm{mm})$ & $\begin{array}{c}\text { Number } \\
\text { of nodes }\end{array}$ & $\begin{array}{c}\text { Number of } \\
\text { elements }\end{array}$ & $\begin{array}{c}\text { Computation } \\
\text { time }\end{array}$ & $\begin{array}{c}\text { Mold filling } \\
\text { time (s) }\end{array}$ \\
\hline \multirow{3}{*}{3.175} & 1.588 & 1554 & 1720 & $17 \mathrm{~m} 42 \mathrm{~s}$ & 201 \\
\cline { 2 - 6 } & 2.381 & 1554 & 1720 & $17 \mathrm{~m}$ & 173 \\
\cline { 2 - 6 } & 3.175 & 1407 & 1600 & $13 \mathrm{~m} 37 \mathrm{~s}$ & 155 \\
\hline \multirow{4}{*}{6.350} & 1.588 & 2520 & 3480 & $45 \mathrm{~m} 58 \mathrm{~s}$ & 294 \\
\cline { 2 - 6 } & 2.381 & 2520 & 3480 & $44 \mathrm{~m} 20 \mathrm{~s}$ & 237 \\
\cline { 2 - 6 } & 3.175 & 2373 & 3360 & $38 \mathrm{~m} 41 \mathrm{~s}$ & 202 \\
\cline { 2 - 6 } & 4.763 & 2121 & 2880 & $28 \mathrm{~m} 24 \mathrm{~s}$ & 175 \\
\cline { 2 - 6 } & 6.350 & 1995 & 2680 & $24 \mathrm{~m} 12 \mathrm{~s}$ & 146 \\
\hline \multirow{4}{*}{9.525} & 1.588 & 3486 & 5240 & $1 \mathrm{~h} 22 \mathrm{~m} 23 \mathrm{~s}$ & 397 \\
\cline { 2 - 6 } & 2.381 & 3486 & 5240 & $1 \mathrm{~h} 19 \mathrm{~m} 25 \mathrm{~s}$ & 313 \\
\cline { 2 - 6 } & 3.175 & 3339 & 5120 & $1 \mathrm{~h} 11 \mathrm{~m} 47 \mathrm{~s}$ & 259 \\
\cline { 2 - 6 } & 4.763 & 3087 & 4640 & $57 \mathrm{~m} 47 \mathrm{~s}$ & 217 \\
\cline { 2 - 6 } & 6.350 & 2709 & 3960 & $41 \mathrm{~m} 56 \mathrm{~s}$ & 182 \\
\cline { 2 - 6 } & 9.525 & 2394 & 3400 & $30 \mathrm{~m} 17 \mathrm{~s}$ & 138 \\
\hline
\end{tabular}

If the mold filling time when $d_{\text {gate }}=h$ is used as the reference, the dimensionless gate diameter and mold filling time are derived as

$$
\begin{aligned}
& d_{\text {gate }}^{*}=d_{\text {gate }} / h \\
& t_{\text {fill }}^{*}=t_{\text {fill }} /\left.t_{\text {fill }}\right|_{d_{\text {gate }}=h}
\end{aligned}
$$


The dimensionless mold filling time is plotted vs. dimensionless gate diameter in Figure 15 based on the data as shown in Table 2. It shows that $t_{\text {fill }}^{*}$ is dependent on $d_{\text {gate }}^{*}$ and a regression model can be developed as

$$
t_{\text {fill }}^{*}=\left(d_{\text {gate }} / h\right)^{-1 / 2}
$$

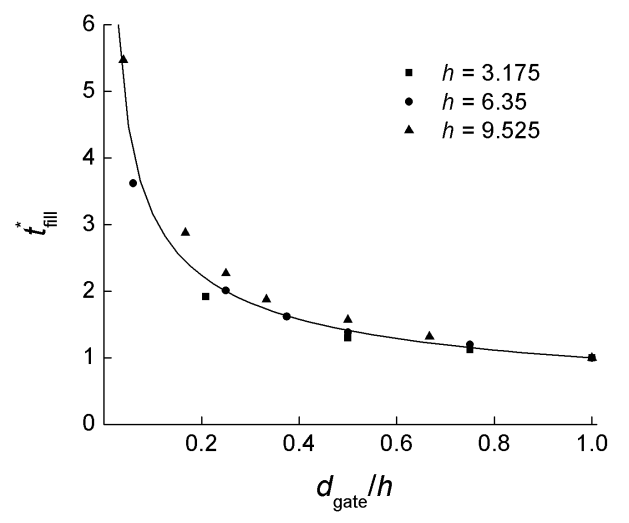

Figure 15: Dimensionless mold filling time vs. dimensionless gate diameter

\subsection{2-D Gate Definition}

In the 2-D LCM simulation, cross section of the gate cannot be modeled. In order to correctly incorporate the gate size effect in simulation, the gate can be regarded as a rectangle of which the two sides are the molding thickness $h$ and the gate width in 2-D simulation $\hat{w}_{\text {gate }}$, and its equivalent diameter is the gate diameter in 3-D simulation $\hat{d}_{\text {gate }}$, as shown in Figure 16. 


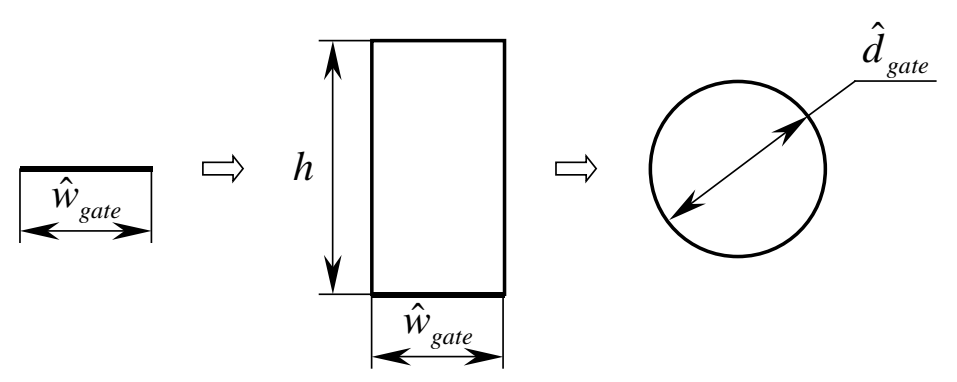

Figure 16: 2-D gate definition

For a flow channel of rectangular cross-section, the equivalent diameter is given by [20]

$$
\hat{d}_{\text {gate }}=\left(128 h \hat{w}_{\text {gate }}^{3} / \pi K\right)^{0.25}
$$

where $K$ is a constant given by

\begin{tabular}{ccccccccc}
\hline$h / \hat{w}_{\text {gate }}$ & 1 & 1.5 & 2 & 3 & 4 & 5 & 10 & $\infty$ \\
$K$ & 28.45 & 20.43 & 17.49 & 15.19 & 14.24 & 13.73 & 12.81 & 12 \\
\hline
\end{tabular}

The width of the gate in 2-D simulation is given by

$$
\hat{w}_{\text {gate }}=\left[\hat{d}_{\text {gate }}^{4} \pi K /(128 h)\right]^{1 / 3}
$$

When the molding thickness is $3.175 \mathrm{~mm}, 6.35 \mathrm{~mm}$, and $9.525 \mathrm{~mm}$, respectively, the calculated gate width in 2-D simulation is shown in Table 3. 
Table 3: Gate width in 2-D mold filling simulation

\begin{tabular}{l|l|l|l}
\hline$h(\mathrm{~mm})$ & $d_{\text {gate }}(\mathrm{mm})$ & $\hat{d}_{\text {gate }}(\mathrm{mm})$ & $\hat{w}_{\text {gate }}(\mathrm{mm})$ \\
\hline \multirow{3}{*}{3.175} & 1.588 & 1.123 & 0.547 \\
\cline { 2 - 4 } & 2.381 & 1.684 & 0.972 \\
\cline { 2 - 4 } & 3.175 & 2.245 & 1.498 \\
\hline \multirow{4}{*}{6.350} & 1.588 & 1.123 & 0.425 \\
\cline { 2 - 4 } & 2.381 & 1.684 & 0.736 \\
\cline { 2 - 4 } & 3.175 & 2.245 & 1.094 \\
\cline { 2 - 4 } & 4.763 & 3.368 & 1.945 \\
\cline { 2 - 4 } & 6.350 & 4.490 & 2.997 \\
\hline \multirow{4}{*}{9.525} & 1.588 & 1.123 & 0.369 \\
\cline { 2 - 4 } & 2.381 & 1.684 & 0.636 \\
\cline { 2 - 4 } & 3.175 & 2.245 & 0.940 \\
\cline { 2 - 4 } & 4.763 & 3.368 & 1.641 \\
\cline { 2 - 4 } & 6.350 & 4.490 & 2.461 \\
\cline { 2 - 4 } & 9.525 & 6.735 & 4.495
\end{tabular}

The 2-D simulations were carried out using the gate width calculated shown in Table 3. In order to consider the effect of gate size and avoid singularities, the gate is defined by several nodes in such a way that the width of the control volumes filled at the beginning of mold filling is the gate width. For example, when the molding thickness is $3.175 \mathrm{~mm}$ and the gate diameter is $2.381 \mathrm{~mm}$, the mesh for the gate is shown in Figure 17. Two nodes are used as gate nodes so that the width of the control volumes filled at the beginning of injection is $0.486 \mathrm{~mm}$, which is the half gate width used in simulation, as represented by the shaded area. The mesh consisting of 445 nodes and 404 elements and the corresponding mold filling process are shown in Figure 18. The computation time and mold filling time are $17 \mathrm{~m}$ and $173 \mathrm{~s}$, respectively. The complete 2-D simulation result is shown in Table 4. 


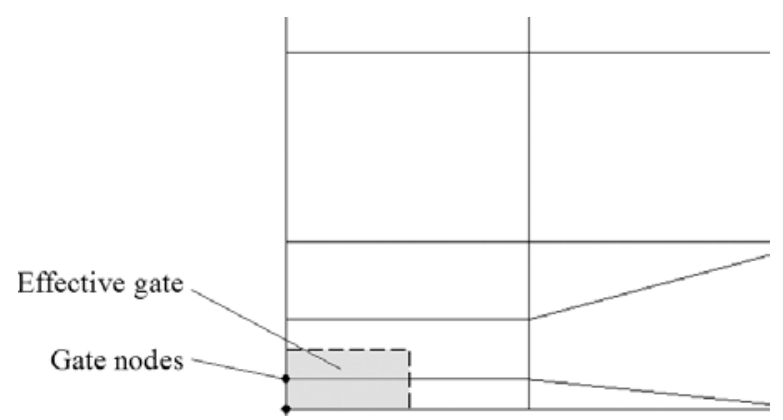

Figure 17: 2-D mesh at the gate when $h=3.175 \mathrm{~mm}$ and $d_{\text {gate }}=2.318 \mathrm{~mm}$
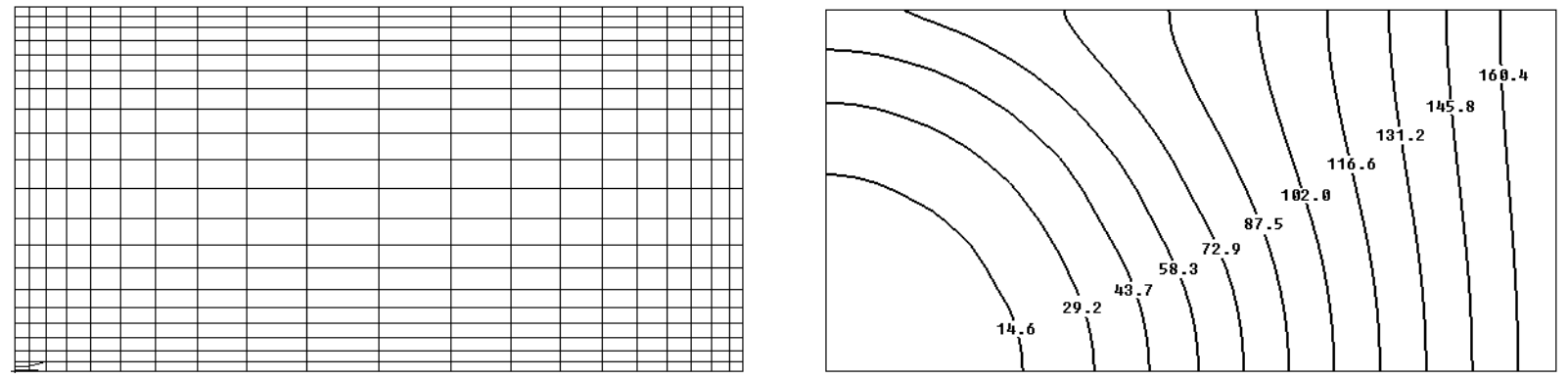

Figure 18: 2-D mesh and mold filling process when $h=3.175 \mathrm{~mm}$ and $d_{\text {gate }}=2.318 \mathrm{~mm}$

Table 4: 2-D CVFEM simulation using the 2-D gate defining method

\begin{tabular}{c|c|c|c|c|c}
\hline$h(\mathrm{~mm})$ & $d_{\text {gate }}(\mathrm{mm})$ & $\begin{array}{c}\text { Number } \\
\text { of nodes }\end{array}$ & $\begin{array}{c}\text { Number of } \\
\text { elements }\end{array}$ & $\begin{array}{c}\text { Computation } \\
\text { time }\end{array}$ & $\begin{array}{c}\text { Mold filling } \\
\text { time (s) }\end{array}$ \\
\hline \multirow{4}{*}{3.175} & 1.588 & 445 & 404 & 32 & 183 \\
\cline { 2 - 6 } & 2.381 & 445 & 404 & 32 & 175 \\
\cline { 2 - 6 } & 3.175 & 443 & 403 & 32 & 163 \\
\hline \multirow{5}{*}{6.350} & 1.588 & 445 & 404 & 33 & 187 \\
\cline { 2 - 6 } & 2.381 & 445 & 404 & 32 & 179 \\
\cline { 2 - 6 } & 3.175 & 445 & 404 & 32 & 173 \\
\cline { 2 - 6 } & 4.763 & 443 & 403 & 31 & 160 \\
\cline { 2 - 6 } & 6.350 & 443 & 402 & 30 & 143 \\
\hline \multirow{5}{*}{9.525} & 1.588 & 445 & 404 & 33 & 189 \\
\cline { 2 - 6 } & 2.381 & 445 & 404 & 33 & 181 \\
\cline { 2 - 6 } & 3.175 & 445 & 404 & 32 & 175 \\
\cline { 2 - 6 } & 4.763 & 443 & 403 & 31 & 162 \\
\cline { 2 - 6 } & 6.350 & 443 & 403 & 30 & 157 \\
\cline { 2 - 6 } & 9.525 & 441 & 400 & 29 & 138 \\
\hline
\end{tabular}

The comparison of 2-D and 3-D mold filling simulation results using the corresponding gate defining method is shown in Figure 19. 

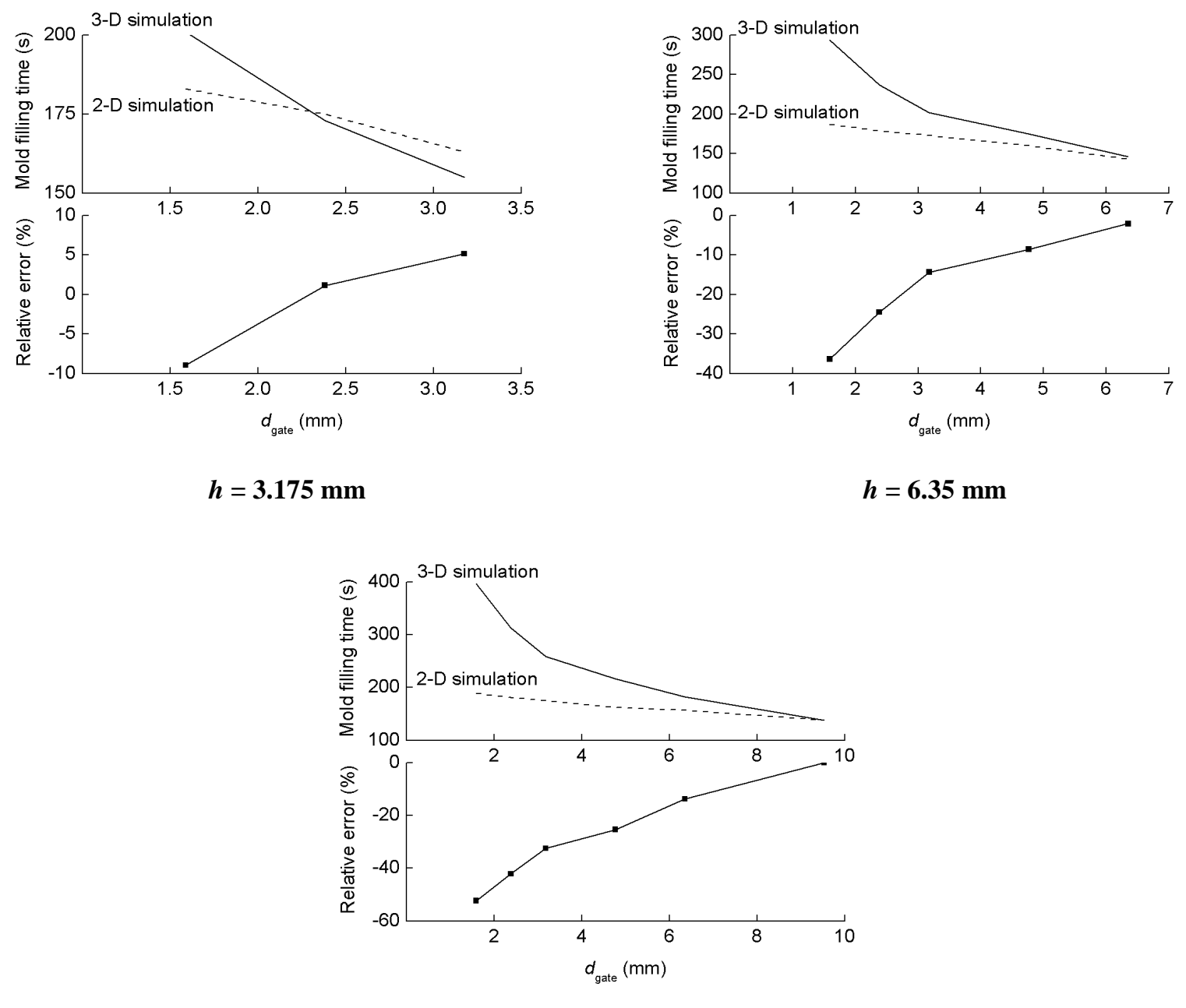

$h=9.525 \mathrm{~mm}$

Figure 19: Comparison of 2-D and 3-D mold filling simulation using corresponding gate defining method

From the results shown in Figure 19, the following conclusions can be made: When $d_{\text {gate }} \approx h$, the 2-D simulation matches the 3-D simulation very well. When $d_{\text {gate }}<h$, the less the gate diameter, the larger the error due to the neglection of through-thickness resin flow. 


\section{Effective Gate Method (EGM)}

Because the 3-D geometric modeling and preprocessing are complicated and timeconsuming, it is highly desirable to conduct mold filling simulation in 2-D. Thus, a practical mold filling simulation method — the Effective Gate Method (EGM) is developed as follows.

1. Construct the 2-D geometric model.

2. Assuming $d_{\text {gate }}=h$, calculate the gate width in simulation and create mesh.

3. Conduct simulation.

4. Calculate the actual mold filling process using $t_{\text {fill }}^{*}=\left(d_{\text {gate }} / h\right)^{-1 / 2}$.

This method was first validated using a part as shown in Figure 20. The molding thickness is $6.35 \mathrm{~mm}$ and the gate diameter is $3.175 \mathrm{~mm} . p_{0}=0.1 \mathrm{MPa} ; \eta=200 \mathrm{cP} ; K_{11}=K_{22}=$ 100 Darcy; $\phi=0.5$. The mesh and mold filling process using the developed EGM are shown in Figure 21. The FE model consists of 188 nodes and 155 elements. The computation time is $2 \mathrm{~s}$ and mold filling time is $177 \mathrm{~s}$. In comparison, the mesh and mold filling process from 3-D simulation are shown in Figure 22. The FE model consists of 1182 nodes and 3745 elements. The computation time is $19 \mathrm{~m} 11 \mathrm{~s}$ and mold filling time is $152 \mathrm{~s}$. If the mold filling time from the 3-D simulation is used as the reference, the relative mold filling simulation error is defined as

$$
\varepsilon=\left|t_{\mathrm{EGM}}-t_{3-\mathrm{D}}\right| / t_{3-\mathrm{D}}
$$

It shows that by using this developed approach, the relative mold filling simulation error, , is $16.4 \%$ and the time saving is $99.8 \%$. 


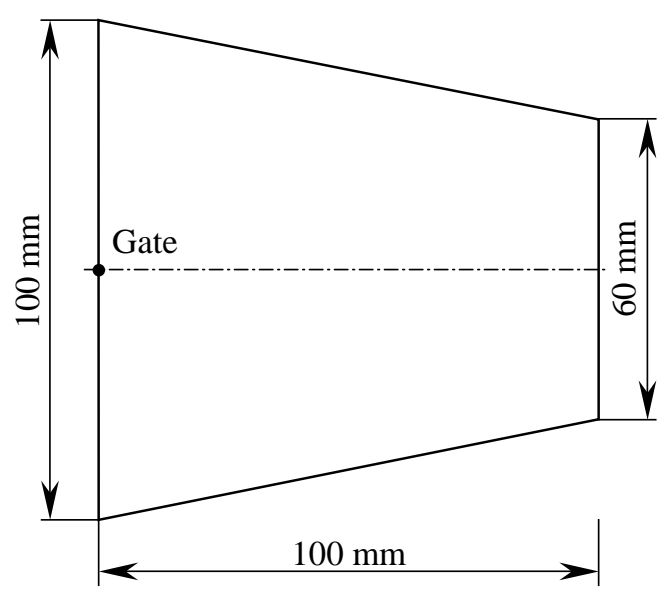

Figure 20: Part for validation
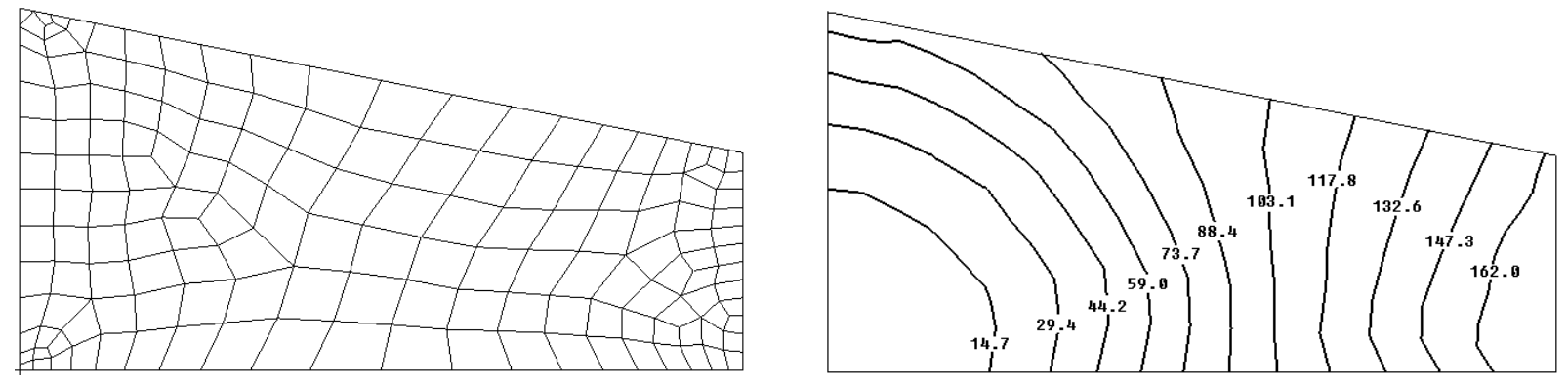

Figure 21: Mesh and mold filling process using GEM
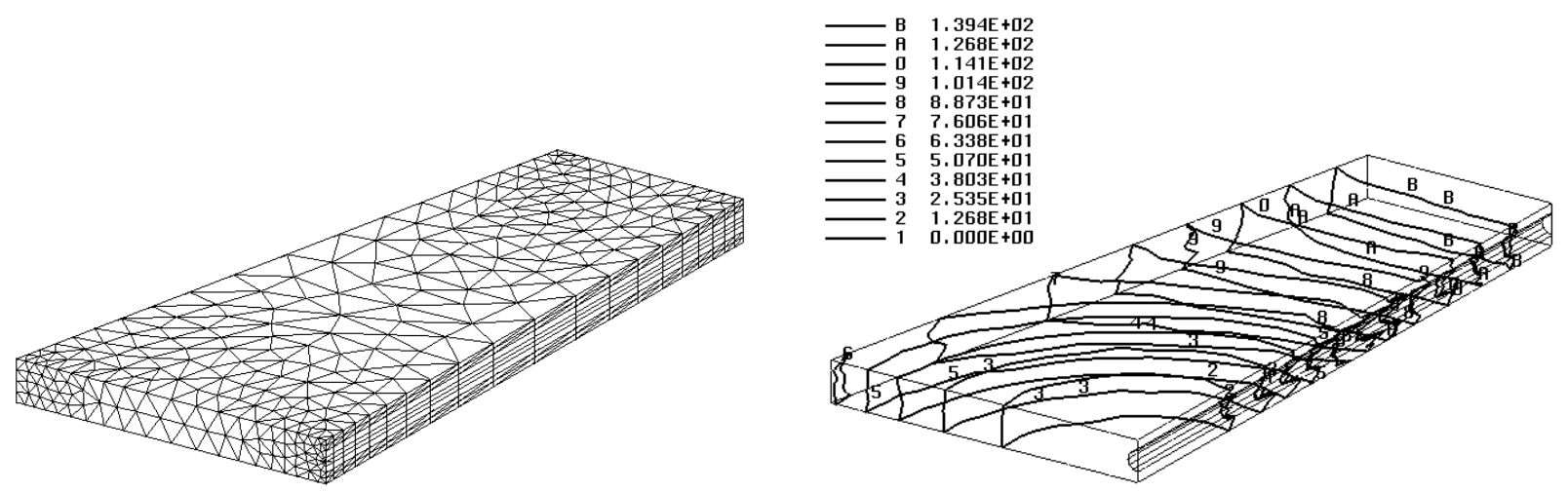

Figure 22: Mesh and mold filling process from 3-D simulation 
Secondly, this method was validated by a curved part with cut-out as shown in Figure 23. The approximate dimensions are $100 \times 100 \mathrm{~mm}$. The molding thickness is $6.35 \mathrm{~mm}$ and the gate diameter is $6.35 \mathrm{~mm} . p_{0}=0.1 \mathrm{MPa} ; \eta=200 \mathrm{cP} ; K_{11}=K_{22}=100$ Darcy; $\phi=0.5$. The mesh and mold filling process using the developed EGM are shown in Figure 24. The FE model consists of 461 nodes and 408 elements. The computation time is 41 s and mold filling time is 142 s. In comparison, the mesh and mold filling process from 3-D simulation are shown in Figure 25. The FE model consists of 2144 nodes and 2976 elements. The computation time is 32m34s and mold filling time is 132s. It shows that by using this developed approach, the relative mold filling simulation error is $7.6 \%$ and the time saving is $98 \%$.

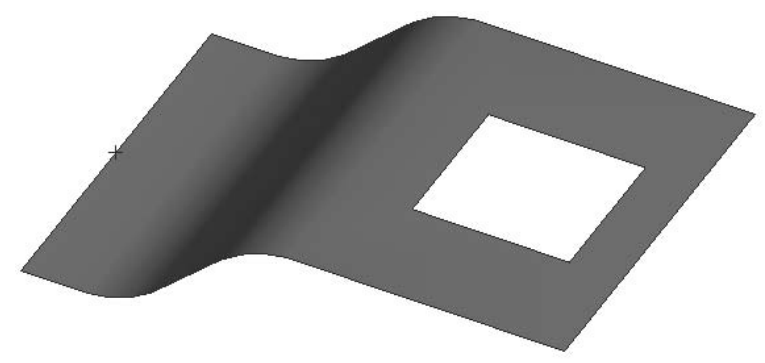

Figure 23: Curved part with cut-out for validation
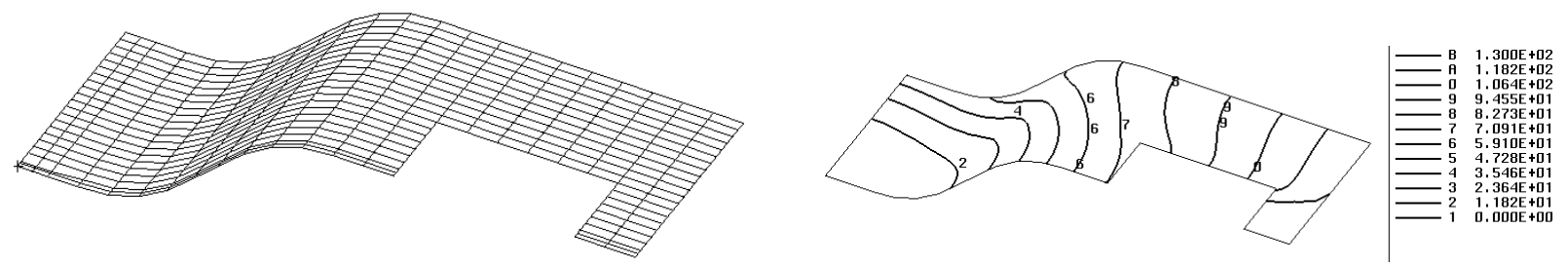

Figure 24: Mesh and mold filling process using GEM 

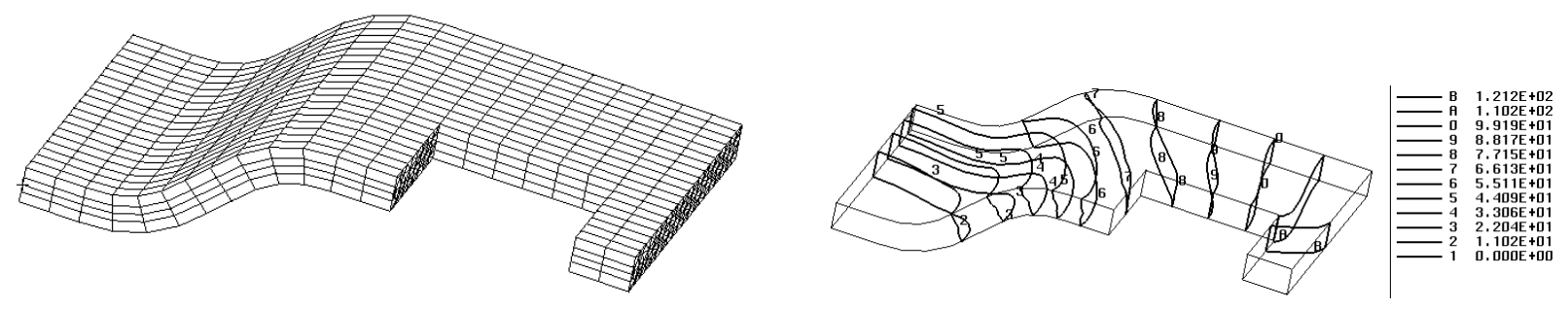

Figure 25: Mesh and mold filling process from 3-D simulation

\section{Conclusions}

In the CVFEM based mold filling simulation, the mesh is critical to the simulation accuracy and efficiency. After an analysis of the errors of mold filling simulation, the main error sources were identified as:

1. The mesh density near gates and vents

2. The gate definition

In order to improve the accuracy of mold filling simulation, fine meshes should be used at the region near the gates and vents. The gate should be defined by several nodes to account for the gate size. Based on the 3-D and 2-D gate defining method study, a method for mold filling simulation incorporating the gate size effect — Effective Gate Method (EGM) was developed. This method was validated through two case studies. It shows that the EGM provides an effective and efficient approach to CVFEM mold filling simulation incorporated the effect of injection gate size.

\section{Nomenclature}

$$
d_{\text {gate }} \quad \text { gate diameter }
$$




$\begin{array}{lll}d_{\text {gate }}^{*} & = & \text { dimensionless gate diameter } \\ \hat{d}_{\text {gate }} & = & \text { gate diameter in 3-D mold filling simulation } \\ h & = & \text { molding thickness } \\ K_{11}, K_{22} & = & \text { in-plane permeability } \\ K_{33} & = & \text { components of permeability tensor } \\ K_{i j}(i, j=x, y, z) & = & \text { normal components of the surface vector of the control }\end{array}$
volume

$\begin{array}{lll}p: & = & \text { pressure } \\ p_{0}: & = & \text { injection pressure } \\ Q & = & \text { flow } \\ t_{\text {fill }} & = & \text { mold filling time } \\ t_{\text {fill }}^{*} & = & \text { dimensionless mold filling time } \\ u, v, w & = & \text { components of velocity } \\ v_{m} & = & \text { maximum velocity of flow through a tube } \\ x, y, z & = & \text { coordinates } \\ \hat{w}_{\text {gate }} & = & \text { gate width in 2-D mold filling simulation } \\ \phi & = & \text { porosity } \\ \eta & = & \text { viscosity }\end{array}$




\section{References}

[1] Gotowsky, T.G. (1997). Advanced Composite Manufacturing, John Wiley \& Sons, New York.

[2] Coulter, J.P. and Guceri, S.I. (1988). Resin Transfer Molding: Process Review, Modeling and Research Opportunities, Proceedings of Manufacturing International '88, v 1, Manufacturing Science of Composites, Atlanta, GA, USA.

[3] Um, M.K. and Lee, W.I. (1991). A Study on Mold Filling Process in Resin Transfer Molding, Polymer Engineering and Science, 31(11): 765-771.

[4] Yoo, Y.E. and Lee, W.I. (1996). Numerical Simulation of the Resin Transfer Mold Filling Process Using Boundary Element Method, Polymer Composites, 17(3): 368-374.

[5] Osswald, T. and Tucker, C. (1987). A Boundary Element Simulation of Compression Mold Filling, Polymer Engineering and Science, 28(7): 413-420.

[6] Béchet, E., Ruiz, E., Trochu, R. and Cuilliere, J.-C. (2004). Re-meshing Algorithms Applied to Mould Filling Simulations in Resin Transfer Moulding, Journal of Reinforced Plastics and Composites, 23(1): 17-36.

[7] Chang, W. and Kikuchi, N. (1994). An Adaptive Remeshing Method in Simulation of Resin Transfer Molding (RTM) Process, Computer Methods in Applied Mechanics and Engineering, 112: 41-68.

[8] Bruschke, M.V. and Advani, S.G. (1991). Filling Simulation of Complex ThreeDimensional Shell-Like Structures, SAMPE Quarterly, 23(1): 2-11. 
[9] Young, W.B., Han, K., Fong, L.H. and Lee, L.J. (1991). Flow Simulation in Molds with Preplaced Fiber Mats, Polymer Composites, 12(6): 391-404.

[10] Liu, X.L. (2000). Isothermal Flow Simulation of Liquid Composite Molding, Composites Part A, 31A(12): 1295-1302.

[11] Lin, R.J., Lee, L.J. and Liou, M.J. (1991). Non-Isothermal Mold Filling and Curing Simulation in Thin Cavities with Preplaced Fiber Mats, International Polymer Processing, VI(4): 356-369.

[12] Young, W.B. (1994). Three-Dimensional Nonisothermal Mold Filling Simulation in Resin Transfer Molding, Polymer Composites, 15(2): 118-127 (1994).

[13] Lee, L.J., Young, W.B. and Lin, R.J. (1994). Mold Filling and Curing Modeling of RTM and SCRIM Processes, Composite Structures, 27(1-2): 109-120.

[14] Simacek, P. and Advani, S.G. (2004). Desirable Features in Mold Filling Simulations for Liquid Molding Processes, Polymer Composites, 25(4): 355-367.

[15] Bruschke, M.V. and Advani, S.G. (1990). A Finite Element/Control Volume Approach to Mold Filling in Anisotropic Porous Media, Polymer Composites, 11(6): 398-405.

[16] Joshi, S.C., Lam, Y.C. and Liu, X.L. (2000). Mass Conservation in Numerical Simulation of Resin Flow, Composites Part A, 31A(10): 1061-1068.

[17] Modi, D., Šimáček, P. and Advani, S. (2003). Influence of Injection Gate Definition on the Flow-front Approximation in Numerical Simulations of Mold-filling Processes, International Journal for Numerical Methods in Fluids, 42(11): 1237-1248 
[18] Simacek, P. and Advani, S. (2004). Gate Elements at Injection Locations in Numerical Simulations of Flow through Porous Media: Applications to Mold Filling, International Journal for Numerical Methods in Engineering, 61(9): 1501-1519.

[19] D’Arcy H. (1856). Les Fontaines Publiques de la villa de Dijon, Dalmont, Paris.

[20] Perry, R.H. and Green, D.W. (1997). Perry's Chemical Engineers' Handbook (7th Edition), McGraw-Hill, New York. 